\title{
Upper Cervical Spine Fracture-Dislocation in Patients With Ankylosing Spondylitis: Application of Halo Vest Before and During Posterior Surgery
}

\author{
Haisong Yang \\ Second Affiliated Hospital of Naval Medical University \\ Yuling Sun \\ Second Affiliated Hospital of Naval Medical University \\ Liang Wang \\ Second Affiliated Hospital of Naval Medical University \\ Chunyan Gao \\ Second Affiliated Hospital of Naval Medical University \\ Fengbin Yu \\ Hospital of 72th Army Group \\ Tianming $\mathbf{X u}$ \\ Navy Medical Center of Naval Medical University \\ Xuhua Lu ( $\triangle$ luxhsmmu@163.com ) \\ Second Affiliated Hospital of Naval Medical University
}

\section{Research Article}

Keywords: ankylosing spondylitis, halo vest, fracture-dislocation, cervical spine, closed reduction, posterior surgery

Posted Date: June 4th, 2021

DOI: https://doi.org/10.21203/rs.3.rs-557216/v1

License: (c) (i) This work is licensed under a Creative Commons Attribution 4.0 International License. Read Full License 


\section{Abstract \\ Background}

It is a challenge to reduce and immobilize the broken "bamboo spine", especially for the upper cervical spine, in patients with ankylosing spondylitis (AS) before and during posterior surgery.

\section{Methods}

We retrospectively analyzed the case histories, operations, neurologic outcomes, follow-up data, and imaging records of 17 patients with AS and upper cervical spine fracture-dislocation who underwent surgical treatment in three clinical spine center from 2010 to 2019. A halo vest was used to reduce and immobilize fractured spinal column ends. The neurological injury was evaluated using the American Spinal Injury Association (ASIA) impairment scale score and Japanese Orthopaedic Association (JOA) score before and after operation. Complications and time of bone fusion were recorded.

\section{Results}

Fourteen patients achieved closed anatomical reduction after halo vest application. No displacement in fracture ends and loss of reduction occurred after prone position. No patient presented with secondary neurological deterioration. All patients was performed posterior surgery. The surgery improved the ASIA grade in all patients $(P<0.001)$. The mean JOA score also increased significantly at last follow-up compared to preoperation $(14.5 \pm 2.3$ vs. $9.2 \pm 2.4, P<0.01)$. No severe complication and death occurred. All patients reached solid bony fusion at 12-month follow-up.

\section{Conclusions}

Use of a halo vest before and during the operation is safe and effective in patients with AS who develop upper cervical spine fracture-dislocation. This technique makes positioning, awake nasoendotracheal intubation, nursing, and the operation more convenient. It can also provide satisfactory reduction and rigid immobilization and prevent secondary neurologic deterioration. .

\section{Background}

Ankylosing spondylitis (AS) is a chronic inflammatory spondyloarthropathy characterized by sacroiliitis and axial joint lesions. Degeneration of the affected joints leads to paravertebral benign ossification and ankylosis with the development of "bamboo spine" $[1,2]$. With the progression of AS, fracture-dislocation can occur under slight forces or without force because of the increased vertebral osteoporosis and bony brittle [3]. These spine traumas, which are located at cervical level in $81 \%$ of patients $[4,5]$, are frequently more severe and extremely unstable with associated higher risk of neurological deterioration compared with cervical fractures in the healthy population, because the broken "bamboo spine" behaves similarly as a long-bone fracture with long lever arms $[6,7]$.

Owing to its highly unstable characteristics, initially intact patients may sustain neurological deficit and secondary neurologic deterioration(SND) after weakly protected transfers and manipulation [8,9]. Therefore, these patients should be handled with great care. Reduction and immobilization of fracture is the cornerstone during the whole period of treatment. Rigid collar and skull traction are most often used. However, it has no reduction to fracture in rigid collar and it is not enough to maintain the stability in AS patients. The application of any type of distraction force increased the risk of precipitating a further neurologic decline at the level of an unstable spinal segment, particularly in the cervical spine [10]. Otherwise, traction reduction in the severely kyphotic patient is a technical challenge, first having to provide in-line traction, with the traction bale often $45^{\circ}$ to the horizontal, followed by a gradual reduction in extension [11].

Page 2/12 
The present study was performed to evaluate the safety and efficacy of using a halo vest for reduction and immobilization in patients with AS who develop upper cervical spine fracture-dislocation before and during posterior surgery.

\section{Methods}

\section{Patient population}

The study is based on datas from AS patients with upper cervical spine fracture- dislocation who underwent surgical treatment in three clinical spine center from January 2010 to January 2019. The study design is a retrospective chart review and a radiological follow-up with plain radiographs or computed tomography (CT). The study group consisted of 17 patients (16 men, 1 women; mean age $54.2 \pm 8.9$ years, range $39-70$ years). Of these patients, the mean AS duration was $33.4 \pm 8.8$ years (range, 19-45 years); median follow-up, $22.3 \pm 10.4$ months (range, $12-36$ months).

All patients were evaluated with plain radiography and CT. CT scans were used to find those fractures easy to escape diagnosis on plain radiography due to distorted anatomy, ossified ligament and osteopenia. It can also elucidate the bone detail of the fracture, deformity, and tissues surrounding the fixation site. If the patient presented with neurologic impairment, magnetic resonance imaging (MRI) was performed to differentiate the various causes of cord compression and to identify cord contusion.

\section{Halo vest application and closed reduction}

All vests were obtained from one appliance manufacturer (Fig. 1). The standard technique of crown halo applications involves choosing 4 pin fixation sites. Two pins are placed in the frontal area and two posteriorly, usually in the posterior parietal or parietooccipital areas [12]. The frontal points are usually at the level of the equator intersecting with the mid pupillary lines. This usually avoids the frontal sinus and hence violations through the anterior table. The posterior pin sites should avoid the mastoid air cells [13]. The halo vest is performed immediately after CT or MRI. According to the preexisting alignment and details of fracture-dislocation, reduction was obtained via regulating the length of anterior and posterior bars of halo vest to allow the cervical spine in the position of extension or flexion. Meanwhile, we asked the feeling of patients and evaluate changes of sensation and muscle strength. The bars are connected at all times, maintaining stability at all points of the procedure and minimizing the possibility of slippage or sudden movements. Then the reduction was assessed by X-ray. It was viewed as spine reduction failure if the distance between 2 surgery-restored vertebral bodies was more than $3 \mathrm{~mm}$; and reduction success if 1-3mm; anatomical reduction if less than $1 \mathrm{~mm}$ [14]. Reduction can be performed repeatedly until obtaining a satisfactory restoration. If reduction failed due to the pain response and high muscle tension in the cervical spine, it can be performed again in the operating room after anaesthesia under neurophysiologic monitoring until a satisfactory restoration. It must be noted that all the reduction manipulation should be gentle and gradual with fluoroscopic guidance to prevent secondary or iatrogenic neurologic defecit.

\section{Treatment and operative technique}

Halo vest was always not removed during anesthesia, position and operation. After an awake nasoendotracheal intubation and induction of general anesthesia, the patients needed to take prone position for posterior surgery. The reduction was confirmed using intraoperative radiography after prone position. If there was some minor changes in the fracture ends, we can remanipulated four bars of the halo vest again to obtain the most restoration. Neurophysiologic monitoring, including sensory and motor-evoked potentials, was employed. Then all the patients were performed posterior surgery alone. Pedicle screws were routinely used for fixation in $\mathrm{C} 1$ and $\mathrm{C} 2$. Lateral mass screws were used instead of pedicle screws in subaxial cervicai spine. At least 3 segments below the fracture site in the caudal spine should be fixed.

Follow-up was carried out at 2, 6, 12, 24 and 36 months postoperation. Patients were monitored for neurological and radiographic outcome. The Japanese orthopaedic association (JOA) score and American spinal injury association (ASIA) impairment scale were used to evaluate the neurological status pre- and postoperation. The neurologic status of the patients at last follow-up was used for defining clinical prognosis. Fusion was considered complete when trabecular bone was visible and 
spanned the fracture site. Complications were also recorded such as infection, dysphagia, severe pneumonia, death, screw loosening and breaking, and rod breakage.

Statistical analyses were performed using SPSS for Windows, Version 18.0 (SPSS Inc., Chicago, IL, USA). ASIA grade, bony fusion, and instrumentation complication were interpreted by percentage and statistically analyzed by the Chi-square test. JOA scores were expressed by mean $(X \pm S)$ and analyzed by $t$ test. $P<.05$ was viewed as statistical significance.

\section{Results}

In our series, A low-energy injury of the spine occurred in 9 cases and a high-energy injury in 8 cases. A single spinal segment was involved in each patient. The odontoid fracture occurred in 6 patients, $\mathrm{C} 2$ vertebral body fracture occured in 1 patient, and $\mathrm{C} 2 / 3$ fracture-dislocation occured in 10 patients. Halo vest is performed immediately after CT or MRI. Fourteen patients achieved closed anatomical reduction, 1 with success reduction and 1 with reduction failure because of intolerant of pain in the fracture. For these 2 patients, reduction was performed gently and gradually again after anesthesia and prone position in operating room. All obtained satisfactory restoration. No patient presented with displacement in the fracture ends and loss of reduction after prone position and during operation.(Table 1) 
Table 1

Datas of 17 AS patients with upper cervical spine fracture-dislocation

\begin{tabular}{|c|c|c|c|c|c|c|c|c|c|c|}
\hline $\begin{array}{l}\text { Case } \\
\text { No. }\end{array}$ & $\operatorname{sex}$ & $\begin{array}{l}\text { Age } \\
\text { (year) }\end{array}$ & $\begin{array}{l}\text { Type } \\
\text { of } \\
\text { injury }\end{array}$ & $\begin{array}{l}\text { Surgery } \\
\text { Duration } \\
\text { (min) }\end{array}$ & $\begin{array}{l}\text { Blood } \\
\text { Loss } \\
(\mathrm{ml})\end{array}$ & $\begin{array}{l}\text { Type of } \\
\text { reduction }\end{array}$ & $\begin{array}{l}\text { Second } \\
\text { neurologic } \\
\text { deteriation }\end{array}$ & $\begin{array}{l}\text { ASIA grade } \\
\text { Preoperation } \\
\text { last } \\
\text { follow- up }\end{array}$ & $\begin{array}{l}\text { JOA scores } \\
\text { Preoperation } \\
\text { last } \\
\text { follow- up }\end{array}$ & $\begin{array}{l}\text { Fusion } \\
\text { Time } \\
\text { (month) }\end{array}$ \\
\hline 1 & $M$ & 51 & $\begin{array}{l}\text { FD at } \\
\mathrm{C} 2 / 3\end{array}$ & 122 & 160 & anatomical & No & DE & 816 & 12 \\
\hline 2 & $M$ & 59 & OF & 95 & 90 & anatomical & No & E E & 1717 & 6 \\
\hline 3 & $M$ & 48 & OF & 110 & 150 & anatomical & No & E E & 1717 & 6 \\
\hline 4 & $M$ & 39 & $\begin{array}{l}\text { FD at } \\
\mathrm{C} 2 / 3\end{array}$ & 120 & 180 & anatomical & No & DE & 915 & 6 \\
\hline 5 & $M$ & 55 & $\begin{array}{l}\text { FD at } \\
\mathrm{C} 2 / 3\end{array}$ & 115 & 150 & anatomical & No & $\mathrm{DE}$ & 1217 & 6 \\
\hline 6 & $M$ & 56 & $\begin{array}{l}\text { FD at } \\
\mathrm{C} 2 / 3\end{array}$ & 140 & 300 & successful & No & $C D$ & 710 & 12 \\
\hline 7 & $M$ & 48 & $\begin{array}{l}\text { FD at } \\
\mathrm{C} 2 / 3\end{array}$ & 120 & 130 & anatomical & No & DE & 1116 & 6 \\
\hline 8 & $M$ & 68 & OF & 135 & 180 & anatomical & No & E E & 1717 & 6 \\
\hline 9 & $M$ & 70 & $\begin{array}{l}\text { FD of } \\
\text { C2 }\end{array}$ & 130 & 200 & anatomical & No & EE & 1717 & 6 \\
\hline 10 & $\mathrm{~F}$ & 65 & $\begin{array}{l}\text { FD at } \\
\mathrm{C} 2 / 3\end{array}$ & 96 & 120 & anatomical & No & $C D$ & 812 & 6 \\
\hline 11 & $M$ & 51 & OF & 104 & 150 & failed & No & E E & 1717 & 6 \\
\hline 12 & M & 62 & OF & 80 & 100 & anatomical & No & $\mathrm{EE}$ & 1717 & 6 \\
\hline 13 & $M$ & 42 & $\begin{array}{l}\text { FD at } \\
\mathrm{C} 2 / 3\end{array}$ & 116 & 170 & anatomical & No & DE & 1115 & 6 \\
\hline 14 & $M$ & 43 & $\begin{array}{l}\mathrm{FD} \text { at } \\
\mathrm{C} 2 / 3\end{array}$ & 134 & 240 & anatomical & No & $C E$ & 614 & 12 \\
\hline 15 & $M$ & 53 & OF & 95 & 140 & anatomical & No & E E & 1717 & 6 \\
\hline 16 & $M$ & 57 & $\begin{array}{l}\text { FD at } \\
\mathrm{C} 2 / 3\end{array}$ & 108 & 190 & anatomical & No & $C E$ & 713 & 12 \\
\hline 17 & $M$ & 54 & $\begin{array}{l}\text { FD at } \\
\mathrm{C} 2 / 3\end{array}$ & 105 & 270 & anatomical & No & DE & 1317 & 6 \\
\hline
\end{tabular}

Seven patients showed no neurologic impairment and they all could walk freely with halo vest under supervision. Two patients experienced secondary neurologic deterioration under only rigid collar fixation in other hospital. There is no further deterioration after halo vest fixation in our hospital. The other 8 patients with neurologic deficit showed no secondary neurologic deterioration after halo vest application. These 10 patients with neurologic impairment could all take semi-reclining or sitting position.

All patients were surgically treated via posterior surgery alone. The median operation duration was $113.2 \pm 16.5$ minutes, and bleeding volume in surgery was $171.8 \pm 56.4 \mathrm{ml}$. The patients with severe complication, including infection, cardiac arrest, heart failure, and respiratory failure were not found. No death case occurred within perioperative. One died because of traffic accident two and half years after operation. There is no new neurologic deficit in the 7 intact patients. The neurological lesion of other 
cases was recovered to different degrees at last follow-up, 2 from Grade $C$ to $D, 2$ from Grade $C$ to $E$, and 6 from grade $D$ to $E$ by ASIA classification, and there is significant difference between post- and preoperation $(P<0.001)$. The mean JOA score also increased significantly at last follow-up compared to preoperation $(14.5 \pm 2.3 \mathrm{vs}$. $9.2 \pm 2.4, \mathrm{P}<0.01)$. (Table 2 )

Table 2

Statistical analysis of the evaluation on surgical outcome

\begin{tabular}{|lll|}
\hline Assessment of time point & AISA & JOA \\
& grade & score \\
\hline preoperation & $3.6 \pm 0.5$ & $9.2 \pm 2.4$ \\
\hline Final follow-up & $4.8 \pm 0.4$ & $14.5 \pm 2.3$ \\
\hline $\mathrm{t}$ & 8.5 & 4.1 \\
\hline$P$ & $<0.001$ & $<.01$ \\
\hline $\begin{array}{l}\text { AISA Grades of patients were evaluated as A, B, C, D, and E from poor to good. For statistical analysis wise, } 5 \text { Frankel Grades } \\
\text { were defined as continuous variables } \mathrm{A}=1, \mathrm{~B}=2, \mathrm{C}=3, \mathrm{D}=4 \text { and } \mathrm{E}=5 \text {, and were analyzed by the paired t-test. }\end{array}$ \\
\hline
\end{tabular}

The radiological follow-up has not shown any signs of disturbed healing, non-unions or loosening of implants. The rate of spine bony fusion was $76.5 \%$ after 6 months postoperation and 100\% before 12 months postoperation.

\section{Illustrated cases}

\section{Case 1}

A 51-year-old man complained of numbness and weakness of the right limbs after falling down. Radiologic imaging is shown in Fig. 2. Halo vest was performed immediately after examination and anatomical reduction was achieved. He could take a semireclining position on bed. Posterior fixation and fusion alone was performed. After operation, the patient showed good neurological improvement from the spinal cord injury. His preoperative JOA score was 8 and postoperative JOA score at last follow-up was 16 , for an improvement rate of $88.9 \%$. According to AISA classification, the grade of neurologic function improved to $\mathrm{E}$ from D.There was no complication during the treatment. The 12-month-postoperative CT showed solid fusion.

\section{Case 2}

A 62-year-old man came to the emergency room after traffic accident, complaining severe neck pain. There was no complaint of numbness and weakness of limbs. Radiologic examination is shown in Fig. 3. Halo vest was performed immediately after examination, but closed reduction failed because of pain in the neck. After anesthesia and prone position, reduction was performed again and a satisfactory restoration was obtained. Posterior fixation and fusion alone was performed. After the operation, there was no nerologic deficit. The 24-month-postoperative CT showed good fusion at fracture site.

\section{Discussion}

The original model of modern Halo vest was first introduced by Perry and Nickel in 1959 for the treatment of patients with poliomyelitis [15]. Holla M found that the halo-vest was the most restrictive immobilizer and reduced movement of the cervical spine substantially for flexion-extension and lateral bending, and nearly complete for rotation [16]. So we use halo vest to achieve reduction and immobilization by regulating the length of anterior and posterior bars of the halo vest for upper cervical spine fracture-dislocation in patients with AS. According to our experiences, there are three following advantages. First, they can walk freely with the vest in the ward for those neurologic intact patients. No lying in bed makes nursing convenient and decreases the perioperative complication. Secondly, there is no worry about displacement of fracture sites when an awake nasoendotracheal intubation and prone position was performed. Thirdly, closed anatomical reduction via halo vest make surgery to be simple. A standard internal fixation and fusion is enough and there is no need to perform open reduction via 
screws and rods in operation. In our case study, no secondary displacement occured before and during operation after halo vest and all patients obtained satisfactory restoration before incision.

It was reported that secondary deterioration of neurological status was observed in 13.9\% AS patients [17]. The risk of incurring a new onset neurodeficit after a cervical injury in patients with AS is at least 3 times that of the general population [18]. After halo vest fixation in our cases, no patient presented with secondary neurologic deterioration, even they walk freely in the ward. Although halo vest has so many advantages in the reduction and immobilization for upper cervical spine fracture-dislocation in patients with AS, it has a high rate of complications when it is as a non-surgical treatment for these patients, including patient discomfort, dysphagia and aspiration, pin loosening, pin site infection, spinal instability, pin site infections, loss of reduction, and pressure sores [19-21]. The poor tolerability of the halo vest in the elderly has been also questioned [22]. So, halo vest is only used for closed reduction and temporary fixation before and during operation in our case study.

Surgical management is still indicated in patients with neurological deficit, secondary deterioration of neurologic status, unstable fracture configuration, and the presence of an epidural hematoma [10]. The options for surgical fixation of cervical spine fractures are anterior fixation, posterior fixation, and combined anterior- posterior fixation. Because anterior fixation has been associated with higher failure rates, posterior or combined anterior-posterior fixation should be considered $[23,24]$. Numerous case reports and series have demonstrated successful management of cervical spine fractures in patients with AS using posterior fixation alone[25-27]. Payer $\mathrm{M}$ concluded that combined surgical approach with posterior-anterior fixation/fusion has been reported to have many advantages, such as excellent deformity correction, direct and indirect decompression of the spinal cord, immediate stability, permission of early mobilisation without external immobilisation, and excellent maintenance of correction in the absence of relevant neck pain [28]. However, the operation time, total costs, hospitalization lengths and complicationa are higher in combined anterior-posterior approach compared with posterior approach alone [29]. According to Robinson Y, even though surgical treatment is associated with a considerable complication rate, it improved the survival of spinal fractures related to AS [30]. After closed reduction via halo vest, we performed only posterior internal fixation and fusion. All the patients achieved bony fusion in one year. There was a significant improvement in the neurologic function.

Published complication rates of spinal fractures in patients with AS are high, ranging from $30-50 \%$ [31]. Complications are reported at equally high rates in nonsurgically and surgically treated cohorts. Pneumonia and respiratory insufficiency, postoperative deep venous thrombosis, and wound infections are frequent postoperative complications. Westerveld et al found high complication rates in surgically treated patients, including instrumentation failure in $35 \%$, neurologic deterioration in $14 \%$, and wound infection in $10 \%$ [17].The rate of complications in this study is lower than previous estimates because our study only included patients with upper cervical spine fracture who usually presenting with minor neurologic defecit and therefore likely substantially underestimates the true likelihood of adverse events in this patient population.

\section{Conclusions}

Upper cervical spine fracture-dislocation in patients with AS is extremely unstable. The application of Halo vest before and during operation can provide saticfactory reduction and rigid immobilization, prevent second neurologic deterioration and make the surgery simple and safe. Posterior internal fixation and fusion alone can achieve complete bony fusion and good neurologic improvement for these patients.

\section{List Of Abbreviations}

AS: Ankylosing spondylitis

JOA: Japanese Orthopedic Association

ASIA: American Spinal Injury Association

CT: Computed tomography 
MRI: Magnetic resonance imaging

CSF: Cerebrospinal fluid

SND: secondary neurologic deterioration

\section{Declarations}

Ethics approval and consent to participate: The ethical review board of Second Affiliated Hospital of Naval Medical University granted approval to conduct our study. Informed consent was obtained from all subjects and from parents and/or legal guardian of deceased patients. All methods in the study were carried out in accordance with the Helsinki guidelines and declaration.

Consent for Publication: Written informed consent for the publication of image relating to an individual person was obtained from the persons

Availability of data and material: The datasets generated and/or analysed during the current study are not publicly available due to limitations of ethical approval involving the patient data and anonymity but are available from the corresponding author on reasonable request.

Competing interests: The authors declare that they have no competing interests.

Funding: The study was supported by Shanghai Municipal Health Commission (NO.2019LJ14)

\section{Authors' contributions:}

Haisong Yang: Conceptualization, Methodology, Software.

Yuling Sun $₫$ Software, Data curation, Writing- Original draft preparation.

Liang Wang: Software, Validation.

Chunyan Gao® Writing- Reviewing and Editing.

Fengbin Yu: Supervision and Methodology.

Tianming Xu: Visualization, Investigation.

Xuhua Lu : Supervision and Methodology.

Acknowledgements:We thank all the patients involved in the study.

\section{References}

1. Braun J, Sieper J. Ankylosing spondylitis. Lancet. 2007;369:1379-90.

2. Calin A. Ankylosing spondylitis. Clin Rheum Dis. 1985;11:41-60.

3. Boonen A, van der Linden SM. The burden of ankylosing spondylitis. J Rheumatol Suppl. 2006;78:4-11.

4. Feldtkeller E, Vosse D, Geusens P, van der Linden S. Prevalence and annual incidence of vertebral fractures in patients with ankylosing spondylitis. Rheumatol Int. 2006;26: 234-9.

5. Samartzis D, Anderson G, Francis H. Multiple and simultaneous spine fractures in Ankylosing Spondylitis. Spine. 2005;24(1):E11.

6. Argenson C, Lovet J, Sanouiller JL, de Peretti F. Traumatic rotatory displacement of the lower cervical spine. Spine. 1988;13(7):767-73. 
7. Foo D, Sarkarati M, Marcelino V. Cervical spinal cord injury complicating ankylosing spondylitis. Paraplegia. 1985;23:35863.

8. Murray GC, Persellin RH. Cervical fracture complicating ankylosing spondylitis. A report of eight cases and review of the literature. Am J Med 1981;70:1033-41.

9. Podolsky SM, Hoffman JR, Pietrafesa CA. Neurologic complications following immobilization of cervical spine fracture in a patient with ankylosing spondylitis. Ann Emerg Med. 1983;12:578-80.

10. Whang PG, Goldberg G, Lawrence JP, Hong J, Harrop JS, Anderson DG, et al. The management of spinal injuries in patients with ankylosing spondylitis or diffuse idiopathic skeletal hyperostosis: a comparison of treatment methods and clinical outcomes. J Spinal Disord Tech. 2009; 22(2):77-85.

11. Schneider PS, Bouchard J, Moghadam K, Swamy G. Acute Cervical Fractures in Ankylosing Spondylitis An Opportunity to Correct Preexisting Deformity. Spine. 2010;35(7):E248-52.

12. Kang M, Vives MJ, Vaccaro AR. The halo vest: principles of application and management of complications. J Spinal Cord Med. 2003;26(3):186-92.

13. Cheong ML, Chan CY, Saw LB, Kwan MK. Pneumocranium secondary to halo vest pin penetration through an enlarged frontal sinus. Eur Spine J. 2009;18(Suppl): 269-71.

14. He A, Xie D, Cai X, Qu B, Kong Q, Xu C, et al. One-stage surgical treatment of cervical spine fracture- dislocation in patients with ankylosing spondylitis via the combined anterior-posterior approach. Medicine (Baltimore). 2017;96(27):e7432.

15. Perry J, Nickel VL: Total cervical-spine fusion for neck paralysis. J Bone Joint Surg (Am). 1959;41-A(1):37-60.

16. Holla M, Hannink G, Eggen TGE, Daanen RA, Hosman AJF, Verdonschot N. Restriction of Cervical Intervertebral Movement With Different Types of External Immobilizers: A Cadaveric 3D Analysis Study. 2017;42(20): E1182-9.

17. Westerveld LA, Verlaan JJ, Oner FC. Spinal fractures in patients with ankylosing spinal disorders: a systematic review of the literature on treatment, neurological status and complications. Eur Spine J. 2009;18(2):145-56.

18. Schiefer TK, Milligan BD, Bracken CD, et al. In-hospital neurologic deterioration following fractures of the ankylosed spine: a single institution experience. World Neurosurg. 2015;83:775-83.

19. Lee D, Adeoye AL, Dahdaleh NS. Indications and complications of crown halo vest placement: A review. J Clin Neurosci. 2017;40:27-33.

20. Glaser JA, Whitehill R, Stamp WG, Jane JA. Complications associated with the halo-vest. A review of 245 cases. J Neurosurg. 1986;65(6):762-9.

21. Longo UG, Denaro L, Campi S, Maffulli N, Denaro V. Upper cervical spine injuries: indications and limits of the conservative management in Halo vest. A systematic review of efficacy and safety. Injury. 2010;41(11):1127-35.

22. Majercik S, Tashjian RZ, Biffl WL, Harrington DT, Cioffi WG. Halo vest immobilization in the elderly: a death sentence? J Trauma. 2005;59:350-56 [discussion 6-8].

23. Werner BC, Samartzis D, Shen FH. Spinal Fractures in Patients With Ankylosing Spondylitis: Etiology, Diagnosis, and Management. J Am Acad Orthop Surg. 2016; 24(4):241-9.

24. Longo UG, Loppini M, Petrillo S, Berton A, Maffulli N, Denaro V. Management of cervical fractures in ankylosing spondylitis: anterior, posterior or combined approach? Br Med Bull. 2015; 115(1):57-66.

25. Cornefjord M, Alemany M, Olerud C. Posterior fixation of subaxial cervical spine fractures in patients with ankylosing spondylitis. Eur Spine J. 2005;14(4):401-8.

26. Chon H, Park JH. Cervical vertebral body fracture with ankylosing spondylitis treated with cervical pedicle screw: A fracture body overlapping reduction technique. J Clin Neurosci. 2017;41:150-3.

27. Yan L, Luo Z, He B, Liu J, Hao D. Posterior pedicle screw fixation to treat lower cervical fractures associated with ankylosing spondylitis: a retrospective study of 35 cases. BMC Musculoskelet Disord. 2017;18(1):81.

28. Payer M. Surgical management of cervical fractures in ankylosing spondylitis using a combined posterior-anterior approach. J Clin Neurosci. 2006;13(1):73-7. 
29. Kurucan E, Bernstein DN, Mesfin A. Surgical management of spinal fractures in ankylosing spondylitis. J Spine Surg. 2018;4(3):501-8.

30. Robinson Y, Willander J, Olerud C. Surgical Stabilization Improves Survival of Spinal Fractures Related to Ankylosing Spondylitis. Spine. 2015; 40(21):1697-702.

31. Hartmann S, Tschugg A, Wipplinger C, et al. Analysis of the Literature on Cervical Spine Fractures in Ankylosing Spinal Disorders. Global Spine J 2017;7(5): 469-81

\section{Figures}

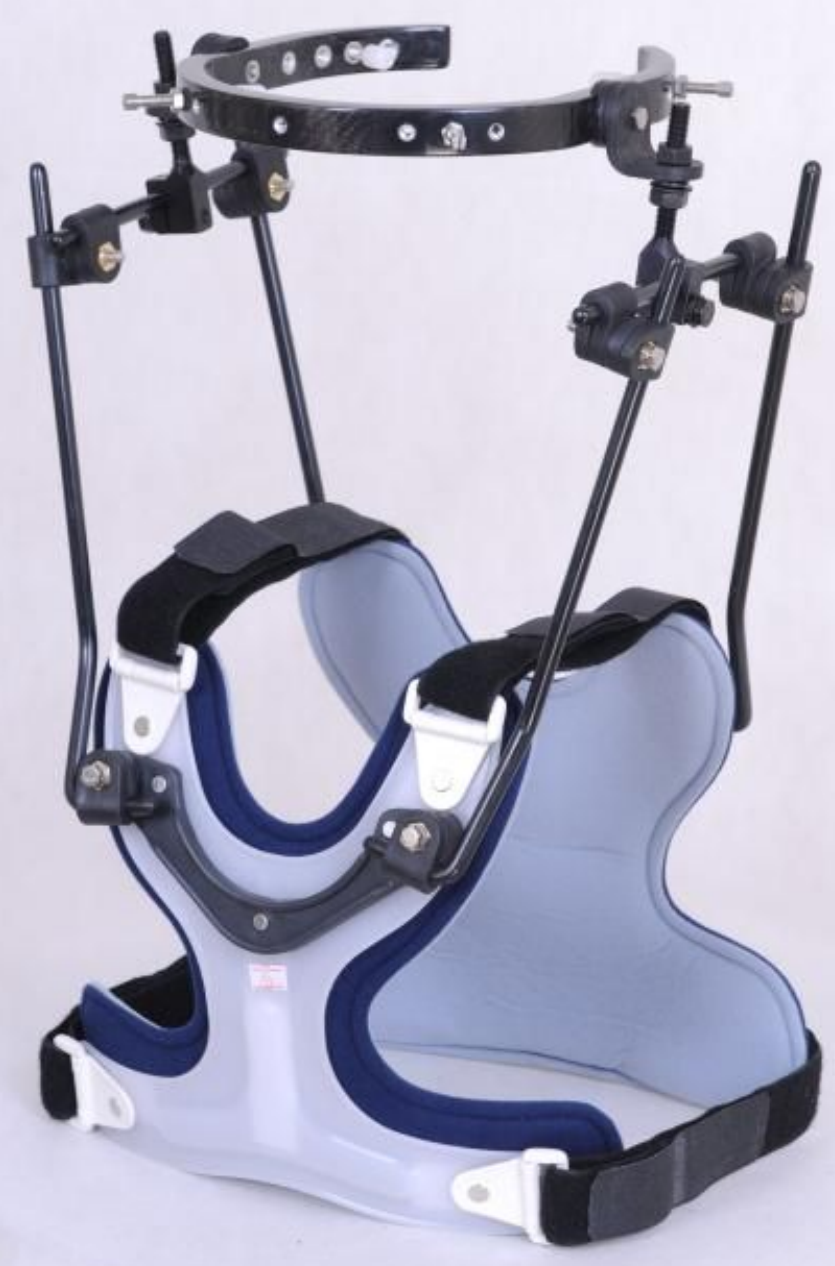

Figure 1

Picture of hao vest. There were three main parts of the halo vest: crown halo, bars and vest. 


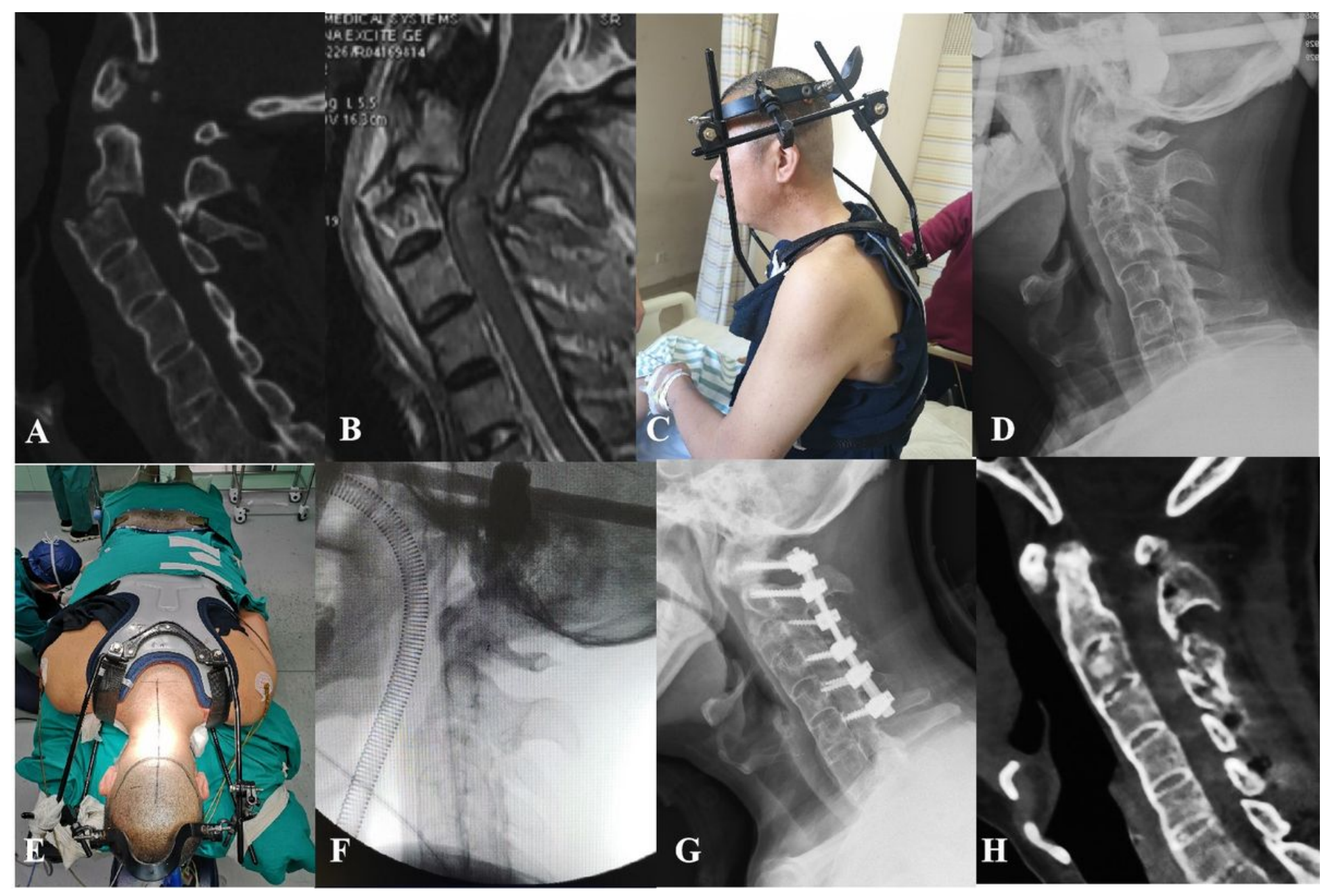

Figure 2

A 51-year-old man with ankylosing spondylitis was diagnosed as $\mathrm{C} 2 / 3$ fracture-dislocation. A. Sagittal CT of the cervical spine showing $\mathrm{C} 2 / 3$ fracture- dislocation. B. Sagittal MRI showing C2/3 fracture-dislocation with spinal cord injury. C. Application of halo vest and sitting position. D. Lateral X-ray after halo vest showing closed anatomical reduction at $\mathrm{C} 2 / 3$. E. Prone position with halo vest. F. No loss of reduction after position. G. Posterior fixation and fusion from C1 to C6. H. sagittal CT at 12-month follow-up showing solid fusion at the fracture site. 


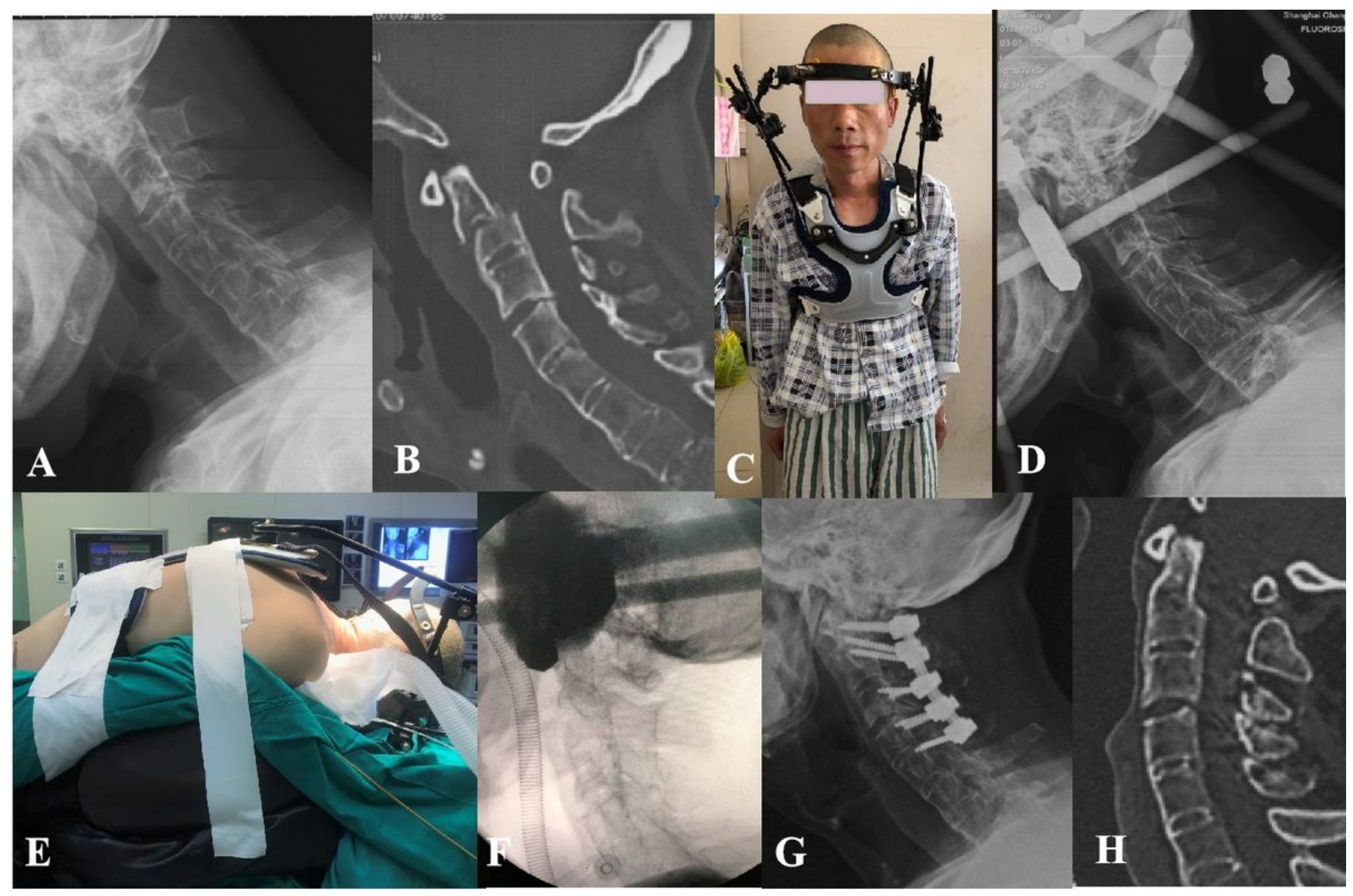

\section{Figure 3}

A 62-year-old man with AS was diagnosed as odontoid fracture and atlantoaxial dislocation. A,B. Lateral X-ray and sagittal CT of the cervical spine showing odontoid fracture and atlantoaxial dislocation. C. Application of halo vest and free standing or walking. D. Lateral X-ray showing a failed reduction. E. Prone position with halo vest. F. Intraoperative radiography showing anatomical reduction after regulating the bars of halo vest again. G. Posterior fixation and fusion was performed from $\mathrm{C} 1$ to $\mathrm{C} 5$. H. Sagittal CT at 24-month follow-up showing solid fusion at the fracture site. 